\title{
PENGAMAN KENDARAAN BERMOTOR DENGAN METODE IDENTIFIKASI DAN SMS
}

\author{
Akuwan Saleh \\ Jurusan Teknik Telekomunikasi, Politeknik Elektronika Negeri Surabaya \\ Institut Teknologi Sepuluh Nopember (ITS), Surabaya, Indonesia \\ Kampus ITS Keputih Sukolilo, Surabaya, 60111 \\ Telp. +62 (31) 5947280 Fax +62 (31) 5946114 \\ E-mail: akuwan@eepis-its.edu
}

\section{ABSTRAK}

Dalam dunia modern, tentunya banyak sekali teknologi yang berkembang. Demikian juga dengan pengaman kendaraan, pada kunci kendaraan bermotor yang digunakan sebagai pengaman kendaraan saat ini dirasa masih kurang aman. Oleh karena itu diperlukan suatu sistem pengaman yang dilengkapi dengan pengiriman informasi ke pemilik. Salah satu sistem yang mendukung kriteria tersebut adalah layanan SMS (Short Message Service). SMS dapat digunakan di mana saja dan kapan saja untuk mengirimkan data dan menerima data secara langsung.

Pada paper ini telah dibuat pengaman kendaraan bermotor dengan metode identifikasi menggunakan barcode dengan fasilitas sms untuk mengirimkan data berupa pemakai kendaraan dengan mikrokontroller sebagai pengontrolnya. Scanner barcode digunakan untuk mendeteksi dan mengidentifikasi siapa saja yang sedang menggunakan kendaraan, dengan cara mengirimkan SMS yang dikontrol oleh mikrokontroller AVR Atmega16. Koneksi antara barcode dan mikrokontroller menggunakan konektor PS2 dan bahasa pemromannya adalah bahasa $C$. Hasil yang telah diperoleh adalah pengiriman informasi berupa karakter, yaitu nama pemakai, pengamanan (on/off) kendaraan yang dapat dilakukan dari jarak jauh dan secara langsung yang dilakukan oleh mikrokontroller ketika diidentifikasi bukan pemakai yang terdaftar serta tidak ada respon dari pemilik dalam waktu yang telah ditentukan sehingga pengaman ini bisa menambah rasa aman bagi pemilik kendaraan karena dapat memberi informasi identitas pemakai kendaraan tersebut.

Kata kunci : Identifikasi ,Scanner barcode, Mikrokontroller, SMS.

\section{PENDAHULUAN}

Banyaknya pencurian kendaraan bermotor (curanmor) akhir-akhir ini, menjadikan kewaspadaan semakin meningkat. Meskipun kendaraan telah dipasang alarm, tetap saja kendaraan tersebut dapat dicuri. Hal tersebut disebabkan karena sistem alarm sudah sangat dikenal bahkan aplikasi yang digunakan pun cukup sederhana.

Barcode merupakan alat yang sangat sering dijumpai di pusat perbelanjaan. Sehingga dengan adanya perkembangan teknologi saat ini, ternyata barcode dapat juga digunakan sebagai sistem pengaman yang tidak dapat ditiru kode-kodenya.

Pengaman kendaraan bermotor yang telah dibuat pada paper ini menggunakan barcode sehingga seperangkat alat tersebut dapat diaplikasikan pada kendaraan bermotor, bersama piranti elektronika yaitu mikrokontroller AVR ATMega16 dan menambahkan fasilitas SMS menggunakan handphone siemen M35i sebagai server.

Dengan merancang database pada mikrokontroller data yang dimasukkan oleh barcode dapat diolah dan terdeteksi atau teridentifikasi dengan baik oleh mikrokontroller. Selanjutnya dilakukan pengecekan identitas pemakai kendaraan yang berasal dari barcode yang sudah dikodekan akan dikirimkan pesan singkat (SMS) berupa informasi pemakai kendaraan ke pemilik kendaraan bermotor tersebut. Dengan demikian pemilik kendaraan dapat mengetahui pemakai kendaraan apakah user yang terdaftar atau user lain yang tidak terdaftar dalam database yang teridentifikasi sebagai pencuri (invalid user).

Pemilik sah kendaraan dapat juga mengontrol (on/off) kendaraan dengan mengirim SMS menggunakan handphone sehingga kendaraan tidak dapat dijalankan oleh pencuri.

Selain itu tujuan dibuatnya pengaman kendaraan ini diharapkan dapat digunakan pada semua kendaraan dan dapat memberikan rasa aman pada pemiliknya, meskipun dalam pengujiannya hanya diimplementasikan pada kendaraan sepeda motor.

\section{LANDASAN TEORI}

\subsection{Barcode}

Barcode yang digunakan pada pengaman kendaraan bermotor ini adalah Tipe 39 [2]. Kode 39 dapat mengkodekan karakter alphanumeric yaitu angka desimal dan huruf besar serta tambahan karakter spesial - $* \$ / \%+$ Satu karakter dalam kode 39 terdiri dari 9 elemen yaitu 5 bar (garis vertikal 
hitam) dan 4 spasi (garis vertikal putih) yang disusun bergantian antara bar dan spasi. 3 dari 9 elemen tersebut memiliki ketebalan lebih tebal dari yang lainnya, 3 elemen yang lebih tebal tersebut terdiri dari 2 bar dan 1 spasi. Elemen yang lebar mewakili digit biner 1 dan elemen yang sempit mewakili digit biner 0 . Untuk dapat membedakan garis vertikal lebar dan sempit maka perbandingan ketebalan antara garis vertikal lebar dan sempit minimum 2:1, dimana perbandingan 3:1 akan lebih baik.

Lebar Keseluruhan Barcode dapat dirumuskan sebagai berikut:

\section{$L=N(3 R X+7 X)+(6 R X+13 X)+(3 R X+7 X)+(M 1+M 2)$}

$$
\text { I II III IV }
$$

dimana :

L : Lebar keseluruhan barcode

$\mathrm{N}$ : Jumlah karakter

$\mathrm{R}$ : Perbandingan garis vertikal lebar dan sempit

$\mathrm{X}$ : Ketebalan garis vertikal sempit

I : LebarNkarakter plusNinter character gap

II : Lebar start dan stop character plus 1 inter character gap antara start character dan character pertama

III : Lebar Check Character plus 1 inter character gap

IV : Lebar 2 kali quiet zone (M1 (start margin) + M2 ( s top margin)).

Check character adalah sisa dari jumlah seluruh nilai karakter dibagi dengan 43, sebagai contoh :

$\begin{array}{ll}\text { Message } & : \text { CODE39 } \\ \text { Karakter } & : \text { C O D E SPACE 3 9 } \\ \text { Nilai karakter } & : 122413143839 \\ \text { Jumlah } & : 12+24+13+14+38+3+9=113 \\ & 113 / 43=2 \text { sisa } 27\end{array}$

27 adalah nilai dari karakter R, maka Message + check character :CODE39R

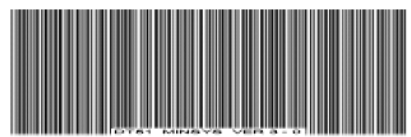

Gambar 1. Contoh Barcode 39

\subsection{Bahasa $\mathrm{C}$}

Akar bahasa $\mathrm{C}$ adalah bahasa BCPL yang dikembangkan oleh Martin Richards pada tahun 1967. Bahasa C adalah bahasa standart, artinya suatu program yang ditulis dengan versi bahasa $\mathrm{C}$ tertentu akan dapat dikompilasi dengan versi bahasa $\mathrm{C}$ yang lain dengan sedikit modifikasi.

Beberapa alasan mengapa bahasa $\mathrm{C}$ banyak digunakan, diantaranya adalah sebagai berikut :

1. Bahasa $\mathrm{C}$ tersedia hampir di semua jenis komputer.

2. Kode bahasa $\mathrm{C}$ sifatnya portabel.
3. Bahasa $\mathrm{C}$ hanya menyediakan sedikit kata kata kunci.

4. Proses executable program bahasa $\mathrm{C}$ lebih cepat.

5. Dukungan Pustaka yang banyak.

6. C adalah bahasa yang terstruktur.

7. Selain bahasa tingkat tinggi, $\mathrm{C}$ juga dianggap sebagai bahasa tingkat menengah.

8. Bahasa $\mathrm{C}$ adalah compiler

\subsection{Mikrokontroller AVR ATmega16}

AVR merupakan seri mikrokontroller CMOS 8-bit buatan Atmel [1], berbasis arsitektur RISC (Reduced Instruction Set Computer). Hampir semua instruksi dieksekusi dalam satu siklus clock. AVR mempunyai 32 register general-purpose, timer/counter fleksibel dengan mode compare, interupt internal dan eksternal, serial UART, programmable Watchdog Timer, dan mode power saving. Beberapa diantaranya mempunyai ADC dan PWM internal. AVR juga mempunyai In-System Programmable Flash on-chip yang mengijinkan memori program untuk diprogram ulang dalam sistem menggunakan hubungan serial SPI. Chip AVR yang digunakan pada tugas akhir kali ini adalah ATmega16. ATmega16 adalah mikrokontroller CMOS 8-bit daya-rendah berbasis arsitektur RISC yang ditingkatkan. Kebanyakan instruksi dikerjakan pada satu siklus clock, ATmega16 mempunyai throughput mendekati 1 MIPS per $\mathrm{MHz}$ membuat disainer sistem untuk mengoptimasi komsumsi daya versus kecepatan proses.

\subsection{Komunikasi Serial}

Baud rate yang digunakan dalam komunikasi serial ini adalah 19200 bps. Penentuan baud rate sangat bergantung pada crystal yang digunakan, crystal ini adalah sebagai oscillator. Crystal yang digunakan adalah $12 \mathrm{MHz}$. Penghitungannya adalah sebagai berikut :

$$
\begin{aligned}
& 19200=\frac{f o s c}{16(U B R R+1)} \\
& 19200=\frac{12 M H z}{16(U B R R+1)}
\end{aligned}
$$

Dengan frekwensi oscillator sebesar $12 \mathrm{MHz}$, sedangkan UBRR dalam format heksa bernilai $026 \mathrm{H}$. 


\subsection{Short Message Service Centre (SMSC)}

Short message service centre (SMSC) adalah kombinasi perangkat keras dan perangkat lunak yang bertanggung jawab memperkuat, menyimpan dan meneruskan pesan pendek antara SMS dan piranti bergerak. SMSC harus memiliki kehandalan , kapasitas pelanggan, dan throughput pesan yang tinggi. Selain itu, SMS juga harus dapat diskalakan dengan mudah untuk mengakomodasikan peningkatan permintaan SMS dalam jaringan yang ada. SMSC mentransfer pesan dalam format Point to point pada sistem yang melayani.

\subsection{Mekanisme Store dan Forward pada SMS}

SMS adalah data tipe asynchoronous message yang pengiriman datanya dilakukan dengan mekanisme protokol store and forward. Hal ini berarti bahwa pengirim dan penerima SMS tidak perlu berada dalam status berhubungan (connected/ online) satu sama lain ketika akan saling bertukar pesan SMS. Pengiriman pesan SMS secara store and forward berarti pengirim pesan SMS menuliskan pesan dan nomor telepon tujuan dan kemudian mengirimkannya (store) ke server SMS (SMSCenter) yang kemudian bertanggung jawab untuk mengirimkan pesan tersebut (forward) ke nomor telepon tujuan. Keuntungan mekanisme store and forward pada SMS adalah, penerima tidak perlu dalam status online ketika ada pengirim yang bermaksud mengirimkan pesan kepadanya, karena pesan akan dikirim oleh pengirim ke SMSC yang kemudian dapat menunggu untuk meneruskan pesan tersebut ke penerima ketika ia siap dan dalam status online di lain waktu. Ketika pesan SMS telah terkirim dan diterima oleh SMSC, pengirim akan menerima pesan singkat (konfirmasi) bahwa pesan telah terkirim (message sent). Hal-hal inilah yang menjadi kelebihan SMS dan populer sebagai layanan praktis dari sistem telekomunikasi bergerak.

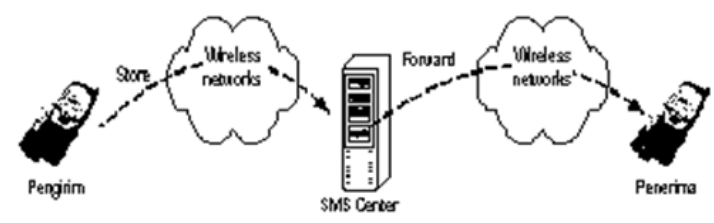

Gambar 2. Mekanisme Store dan Forward

\subsection{AT Command}

Dibalik tampilan menu message pada ponsel sebenarnya adalah AT Command yang bertugas mengirim atau menerima data ke atau dari SMSCenter. AT Command tiap-tiap SMS device bisa berbeda-beda, tetapi pada dasarnya sama. Beberapa AT Command yang penting untuk SMS [6] yaitu :

-AT+CMGS : untuk mengirim SMS

- AT+CMGL : untuk memeriksa SMS

- AT+CMGD : untuk menghapus SMS
AT Command untuk SMS, biasanya diikuti oleh data I/O yang diwakili oleh unit-unit PDU.

\subsection{PDU Sebagai Bahasa SMS dan Bagian - Bagiannya}

Data yang mengalir ke atau dari SMS-Center harus berbentuk PDU (Protocol Data Unit). PDU berisi bilangan-bilangan heksadesimal yang mencerminkan bahasa I/O. PDU terdiri atas beberapa Header. Header untuk kirim SMS ke SMSCenter berbeda dengan SMS yang diterima dari SMS-Center.

Maksud dari bilangan heksadesimal adalah bilangan yang terdiri atas $0,1,2,3,4,5,6,7,8,9, A, B, C, D, E, F$ PDU untuk mengirim SMS terdiri atas delapan header, sebagai berikut :

1. Nomor SMS-Center

2. Tipe SMS

3. Nomor Referensi SMS

4. Nomor Ponsel Penerima

5. Bentuk SMS

6. Skema Encoding Data I/O

7. Jangka Waktu Sebelum SMS Expired

8. Isi SMS

\section{PERANCANGAN SISTEM}

Perancangan sistem yang telah dibuat menggunakan berbagai macam alat, antara lain : sepeda motor, barcode, HP, Komunikasi PS2 dan perangkat lunak untuk program mikrokontroller dan instalasi barcode.

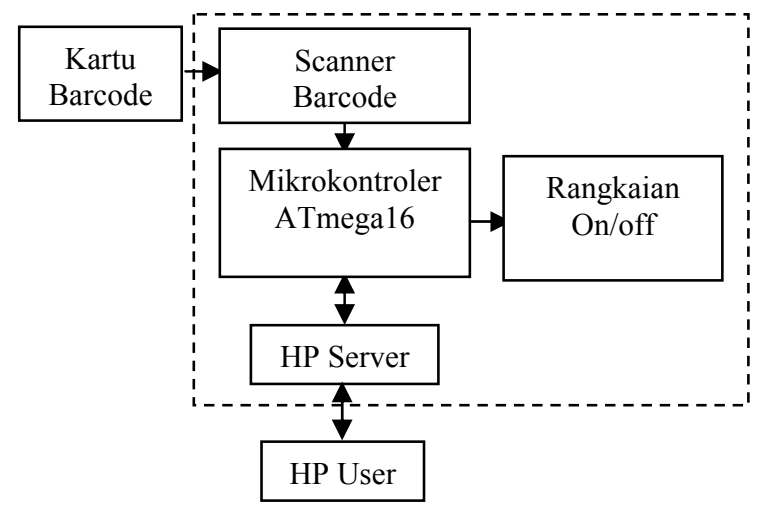

Gambar 3. Blok Diagram Pengaman Kendaraan Bermotor

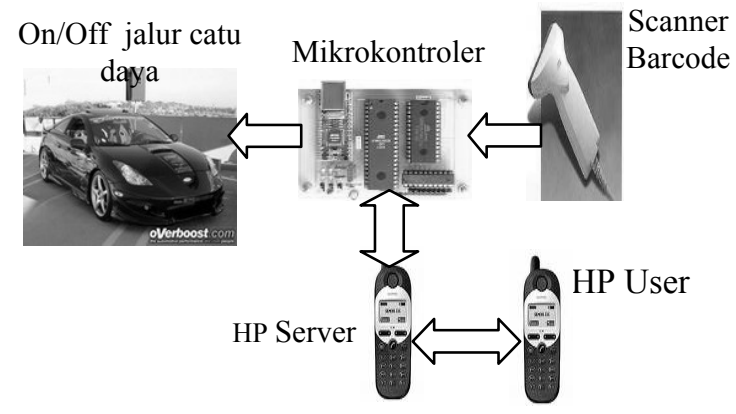


Gambar 4. Rancangan Pengaman Kendaraan Bermotor

Proses kerja sistem yang telah dibuat adalah ketika scanner barcode menerima masukkan, maka scanner barcode akan memproses data tersebut pada mikrokontroller. Apabila datanya telah teregistrasi, maka jalur catu daya pada kendaraan akan on. Begitu juga sebaliknya, apabila data yang dimasukkan tidak terregistrasi maka jalur catu daya pada kendaran akan off. Selanjutnya pengiriman data pemakai kendaraan dengan SMS menggunakan handphone dikerjakan secara otomatis oleh mikrokontroler.

\subsection{Set Up Barcode}

Proses dari setup barcode secara manual diperlihatkan pada gambar berikut.

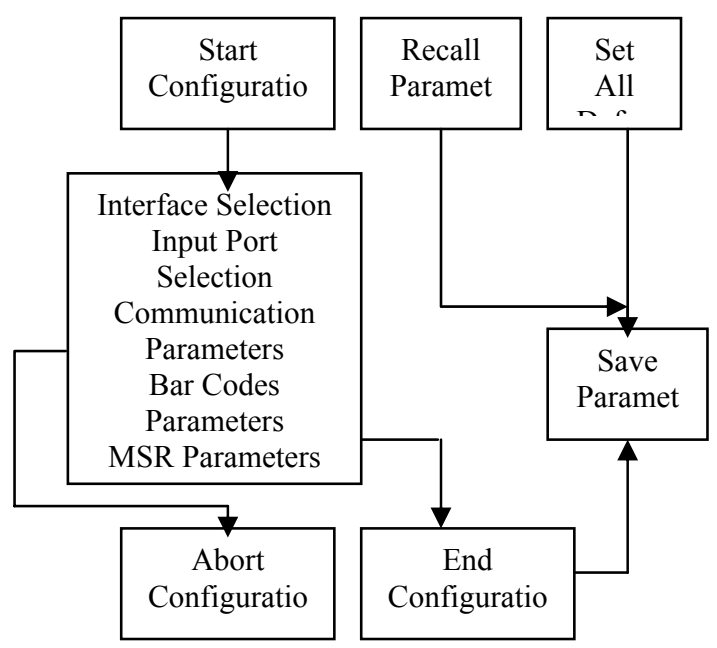

Gambar 5. Set Up Barcode secara Manual

\subsection{Rancangan Perangkat Lunak}

Diagram alir program utama pengaman kendaraan bermotor diperlihatkan pada gambar 6 .

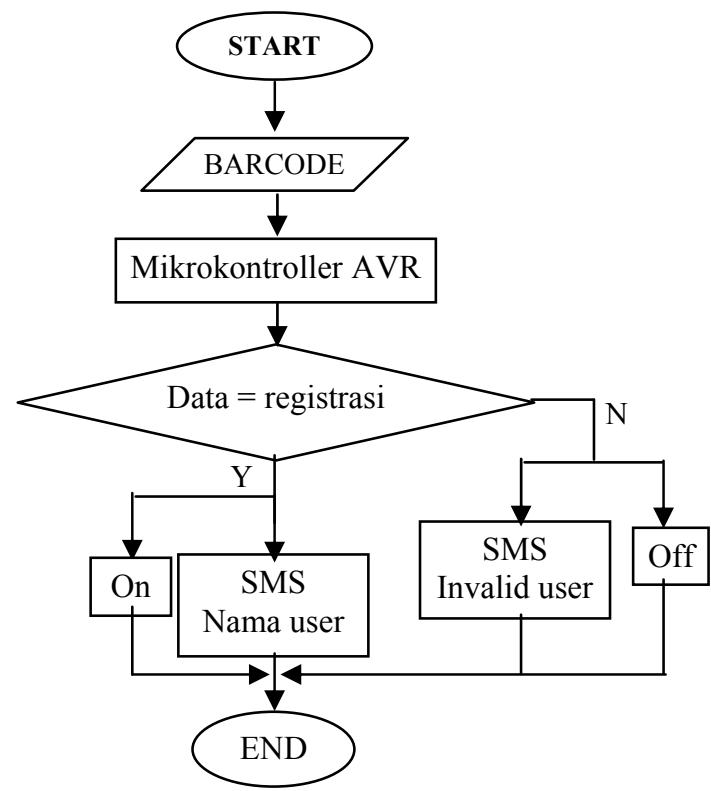

Gambar 6. Flowchart Sistem Pengaman

\section{PENGUJIAN DAN ANALISA}

Pada bagian ini dilakukan pengujian pengaman kendaraan bermotor meliputi pengujian identifikasi pemakai dengan barcode dan mikrokontroler, pengiriman SMS dengan mikrokontroler, Pengujian On/Off jalur catu daya kendaraan dan pengujian integrasi sistem.

\subsection{Pengujian Identifikasi Pemakai dengan Barcode dan Mikrokontroler}

Pada pengujian identifikasi pemakai ini jumlah pemakai yang telah diregistrasi sebanyak 3 pemakai dengan kode pada kartu barcode $43=\mathrm{Al}-$ Devant, 56=Az-Zilka, dan 65=Al-Zahrah sedangkan 1 pemakai yang tidak registrasi dengan kode kartu barcode $=74$. Pengujian dan hasilnya dapat dilihat pada gambar 7. dan tabel 1 .

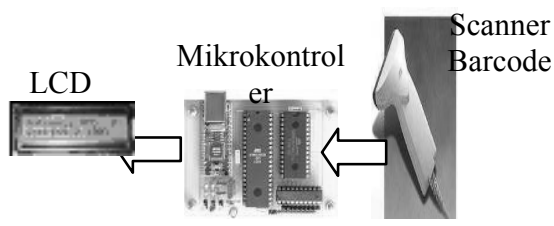

(a) Pengujian identifikasi pemakai

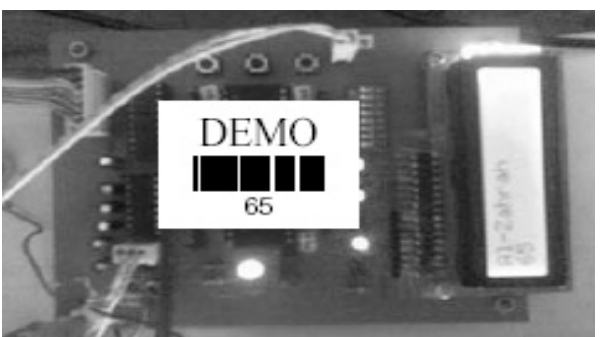

(b) Hasil pengujian user teregistrasi 


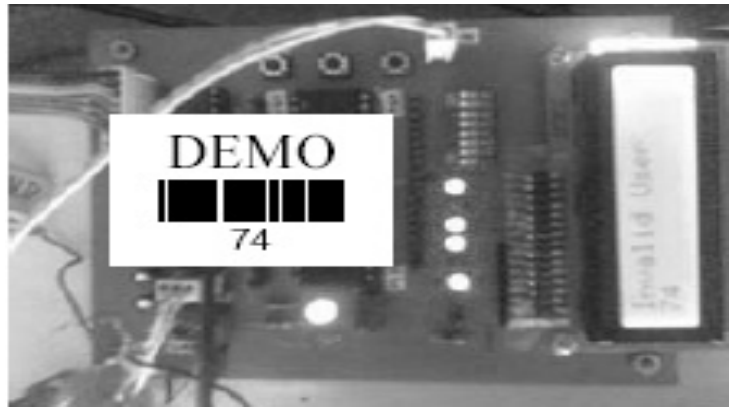

(c) Hasil pengujian user tidak teregistrasi

Gambar 7. Pengujian identifikasi pemakai

Tabel 1. Data hasil identifikasi pemakai

\begin{tabular}{|c|c|c|}
\hline $\begin{array}{c}\text { Kode } \\
\text { Scan }\end{array}$ & $\begin{array}{c}\text { Tampilan } \\
\text { LCD }\end{array}$ & Data Teregistrasi \\
\hline 65 & Al-Zahrah & Ya \\
\hline 74 & Invalid User & Tidak \\
\hline 56 & Az-Zilka & Ya \\
\hline 43 & Al-Devant & Ya \\
\hline
\end{tabular}

\subsection{Pengujian Pengiriman SMS dengan Mikrokontroller}

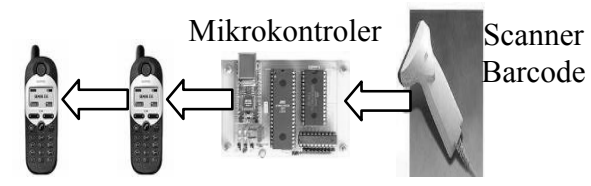

HP User HP Server

Gambar 8. Pengujian pengiriman SMS dengan mikrokontroller

Tabel 2. Hasil pengujian pengiriman SMS dengan mikrokontroler

\begin{tabular}{|c|c|c|c|}
\hline $\begin{array}{c}\text { Kode } \\
\text { Scan }\end{array}$ & Biner & $\begin{array}{c}\text { HP Server } \\
\text { Kirim SMS }\end{array}$ & $\begin{array}{c}\text { HP User } \\
\text { Terima SMS }\end{array}$ \\
\hline 65 & 01000101 & Al-Zahrah & Al-Zahrah \\
\hline 56 & 01010110 & Az-Zilka & Az-Zilka \\
\hline 43 & 01000011 & Al-Devant & Al-Devant \\
\hline 74 & 01110100 & Invalid User & Invalid User \\
\hline
\end{tabular}

\subsection{Pengujian On/Off Jalur Catu Daya Kendaraan}

Setelah pesan Terkirim ke user/pemilik kendaraan maka mesin kendaraan akan on/off secara otomatis karena jalur catu daya dibuka/ditutup oleh mikrokontroler. Prosedur pengujian On/Off kendaraan dengan SMS dan rangkaian relay berfungsi sebagai saklar, memiliki konektor ke sistem pengapian.yang berfungsi on/off kendaraan serta starter motor diperlihatkan pada gambar 9 .

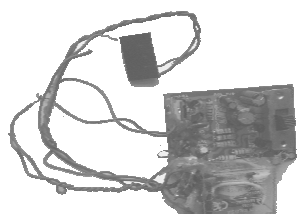

(a). Rangkaian relay berfungsi sebagai saklar

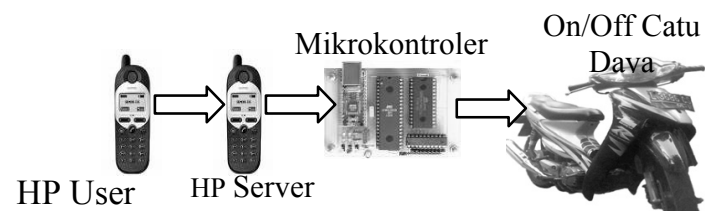

(b). On/Off kendaraan dengan SMS

Gambar 9. Pengujian On/Off catu daya kendaraan

Jika yang dikirim nama-nama yang di kenal maka jalur akan ditutup/on secara otomatis.

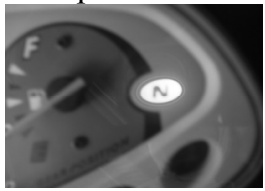

(a). Lampu netral On

Tapi jika tidak di kenali oleh mikrokontroller maka jalur akan diputus/off secara otomatis baik oleh mikrokontroler sendiri karena tidak ada perintah maupun dapat perintah dari HP user/pemilik.

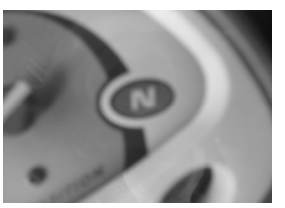

(b). Lampu netral Off

Gambar 10. Lampu netral kendaraan On/Off

Tabel 3. Hasil pengujian On/Off catu daya kendaraan

\begin{tabular}{|c|c|c|}
\hline \multicolumn{2}{|c|}{ HP Server } & \multirow{2}{*}{$\begin{array}{c}\text { Lampu } \\
\text { Netral }\end{array}$} \\
\hline Kirim SMS & Terima Pesan & Nyala \\
\hline Al-Zahrah & ONMESIN & Padam \\
\hline Invalid User & OFMESIN & \\
\hline
\end{tabular}




\subsection{Pengujian Integrasi Sistem}

Hasil pengujian integrasi sistem sesuai rancangan sistem pada gambar 4 adalah sebagai berikut.

Tabel 3. Hasil pengujian integrasi sistem pengaman kendaraan

\begin{tabular}{|c|c|c|c|}
\hline $\begin{array}{l}\text { Kode } \\
\text { Scan }\end{array}$ & $\begin{array}{c}\text { HP } \\
\text { Server } \\
\text { Kirim } \\
\text { SMS } \\
\end{array}$ & $\begin{array}{c}\text { HP User } \\
\text { Terima } \\
\text { SMS }\end{array}$ & $\begin{array}{l}\text { Kondisi } \\
\text { Mensin }\end{array}$ \\
\hline 65 & Al-Zahrah & Al-Zahrah & $\mathrm{ON}$ \\
\hline 56 & Az-Zilka & Az-Zilka & $\mathrm{ON}$ \\
\hline 43 & Al-Devant & Al-Devant & $\mathrm{ON}$ \\
\hline 74 & $\begin{array}{c}\text { Invalid } \\
\text { User }\end{array}$ & $\begin{array}{l}\text { Invalid } \\
\text { User }\end{array}$ & OFF \\
\hline --- & $\begin{array}{c}\text { Invalid } \\
\text { User }\end{array}$ & $\begin{array}{c}\text { Invalid } \\
\text { User }\end{array}$ & $\mathrm{OFF}_{*}$ \\
\hline $\begin{array}{c}\text { HP User } \\
\text { Kirim } \\
\text { SMS }\end{array}$ & $\begin{array}{c}\text { HP } \\
\text { Server } \\
\text { Terima } \\
\text { SMS }\end{array}$ & $\begin{array}{l}\text { Kondisi } \\
\text { Mensin }\end{array}$ & Report \\
\hline $\begin{array}{c}\text { ONMESI } \\
\mathrm{N}\end{array}$ & $\begin{array}{c}\text { ONMESI } \\
\mathrm{N}\end{array}$ & $\mathrm{ON}$ & $\begin{array}{c}\text { ONMESIN } \\
\text { SUKSES }\end{array}$ \\
\hline $\begin{array}{l}\text { OFMESI } \\
\mathrm{N}\end{array}$ & $\begin{array}{c}\text { OFMESI } \\
\mathrm{N}\end{array}$ & OFF & $\begin{array}{l}\text { OFMESIN } \\
\text { SUKSES }\end{array}$ \\
\hline
\end{tabular}

*) Menggunakan barcode tiruan (fotocopy).

\subsection{Analisa}

Dari hasil pengujian sub-sistem maupun integrasi sistem dapat dianalisis sebagai berikut:

- Data dikatakan teregistrasi, apabila data yang diterima oleh mikrokontroller sesuai dengan nama pemakai yang terdapat pada program database yang telah dibuat.

- Data dikatakan tidak teregistrasi, apabila data yang diterima oleh mikrokontroller tidak sesuai dengan nama pemakai yang terdapat pada program database yang telah dibuat.

- Masukkan data dari barcode akan diolah oleh mikrokontroler, apabila data teregistrasi ditampilkan melalui LCD maupun HP user adalah sama yaitu berupa "nama pemakai". Sedangkan jika data tidak teregistrasi ditampilkan melalui LCD maupun HP user adalah berupa "Invalid User".

- Mikrokontroller pada sistem pengaman kendaraan berfungsi sebagai kontrol On/Off kendaraan secara otomatis baik oleh mikrokontroler sendiri karena tidak ada perintah maupun dapat perintah dari HP user/pemilik.

- Perintah kontrol yang diterima oleh mikrokontroler akan dibandingkan dengan data yang terdapat pada database berupa nomor identitas pemilik (No. HP user).

- Barcode yang berupa fotocopy (tiruan), ketika discan tidak didapatkan hasil data. Hal ini disebabkan karena tebal tipis barcode brhasil di deteksi oleh barcode reader (Scanner Barcode).

\section{KESIMPULAN}

Dari hasil pengujian dan implementasi sistem yang telah dilakukan, dapat ditarik kesimpulan bahwa :

1. Kartu barcode dari pemakai yang teregistrasi tidak dapat dibuat tiruannya dengan fotocopy karena tebal dan tipis dari kode bar tersebut dapat dideteksi oleh scanner barcode dengan baik.

2. Sistem minimum yang dibuat dengan mikrokontroller AVR ATMega16 yang dikoneksikan degan HP Server pada pengaman kendaraan dapat memberikan kemudahan bagi pemiliknya untuk melakukan kontrol (On/Off) kendaraan secara jarak jauh.

3. Sistem pengaman kendaraan bermotor yang telah dibuat dapat memberikan dan menambah rasa aman bagi pemilik kendaraan karena dapat memberi informasi identitas pemakai kendaraan tersebut. 


\section{DAFTAR PUSTAKA}

[1] ATmega16(L) Summary at: http://www.atmel.com/dyn/resources/prod_docu ments/2466S.pdf

[2] Code 39 Barcode FAQ and Tutorial at: http://www.idautomation.com/code39faq.html

[3] Iman Ma'rifatul, "Rancang Bangun Sistem Otomatisasi Pintu Garasi Berbasis Mikrokontroller Dengan SMS - Pengontrolan Pintu Otomatis Menggunakan Atmega8535-", PENS/ITS, 2005

[4] Interface RS-232-C at: http://www.lookrs232.com/

[5] PS/2 Keyboard Interface at: http://www.computerengineering.org/index.php?title=PS/2_Keyboard Interface

[5] Kang Bustam, "Trik Pemrograman Aplikasi Berbasis SMS. Jakarta ". PT. Elex Media Computindo, 2002.

[6] Siswoyo Rudi, "Rancang Bangun Sistem Otomatisasi Pintu Garasi Berbasis Mikrokontroller Dengan SMS - Pembuatan Software SMS-", PENS/ITS, 2005

[7] Wardana Lingga, "Belajar Sendiri Mikrokontroller AVR Seri Atmega85835 Simulasi, Hadware, dan Aplikasi ". Andi, Yogyakarta 2006

[8] Yeralan Sencer, Ahluwalia Ashithosh, Programming and Interfacing the 8051 Microcontroller, Addison-Publising Company, New York, 1995. 
